\title{
Transverse Free Vibration of Axially Moving Stepped Beam with Different Length and Tip Mass
}

\author{
Guoliang Ma, ${ }^{1}$ Minglong Xu, ${ }^{1}$ Liqun Chen, ${ }^{2}$ and Zengyong An ${ }^{1}$ \\ ${ }^{1}$ State Key Laboratory for Strength and Vibration of Mechanical Structures, School of Aerospace, Xian Jiaotong University, \\ Xian 710049, China \\ ${ }^{2}$ Department of Mechanics, Shanghai University, Shanghai 200444, China
}

Correspondence should be addressed to Minglong Xu; mlxu@xjtu.edu.cn

Received 10 April 2015; Accepted 26 May 2015

Academic Editor: Rafał Burdzik

Copyright ( 92015 Guoliang Ma et al. This is an open access article distributed under the Creative Commons Attribution License, which permits unrestricted use, distribution, and reproduction in any medium, provided the original work is properly cited.

\begin{abstract}
Axially moving stepped beam (AMSB) with different length and tip mass is represented by adopting Euler-Bernoulli beam theory, and its characteristics and displacements of transverse free vibration are calculated by using semianalytical method. Firstly, the governing equation of the transverse free vibration is established based on Hamilton's principle. The equation is cast into eigenvalue equation through the complex modal analysis. Then, a scheme is proposed to derive the continuous condition accordingly as the displacement, rotation, bending moment, and shear force are all equal at the connections of any two segments. Another scheme is to derive frequency equation from the given boundary conditions which contain a tip mass in the last segment. Finally, the natural frequency and modal function are calculated by using numerical method according to the eigenvalue equation and frequency equation. Due to the introduction of modal truncation, displacement and, the free vibration solution can be obtained by adopting modal superposition after Hilbert transform. The numerical examples illustrate that length, velocity, mass, and geometry affect characteristics and displacements significantly; the series of methods are effective and accurate to investigate the vibration of the AMSB with different length and tip mass after comparing several results.
\end{abstract}

\section{Introduction}

Axially moving structures, simply modeled as axially moving beams (strings) in some cases, are applied in various industrial applications such as magnetic tapes, textile fibers, band saw blades, conveyor belts, transmission chains, aerial cableways, pipes conveying fluid, and steel strips in a thin steel sheet production line. Furthermore, the stepped beam has excellent mechanical properties, constant strength, and optimized distribution of quality, which is also widely used as basic component of many mechanical devices. Moreover, the axially moving stepped beams (AMSB), with different length and tip mass, are made of same or different parts traveling at different speeds; they draw more and more attentions of researchers. There are a wide application and prospect in various fields such as extended arm-type mechanism and air refuelling pipe. This kind of beam actually is multibody system; multibody system analysis (MSA) is an analytical tool used to solve the dynamics problems of complex mechanical systems [1].

There are a number of studies on axially moving systems that have been carried out by scholars in their literatures. Generally, the most important rule is that the inherent frequency and modal function change as the axially moving speed changes. Scholars develop analytical, semianalytical, and numerical methods to investigate the axially moving beams (strings) under different boundary conditions and calculate the natural frequencies, modal functions, responses, and stability at constant or variable speed, which are the major dynamic contents. Mote Jr. [2] firstly calculated the natural frequencies after solving the frequency equation derived from the governing equation of an axially moving beam under pinned-pinned boundary conditions. Simpson [3] presented the frequencies and modal functions under pinned-pinned and clamped-clamped boundary conditions, while the tension effects were not considered. Wickert and 


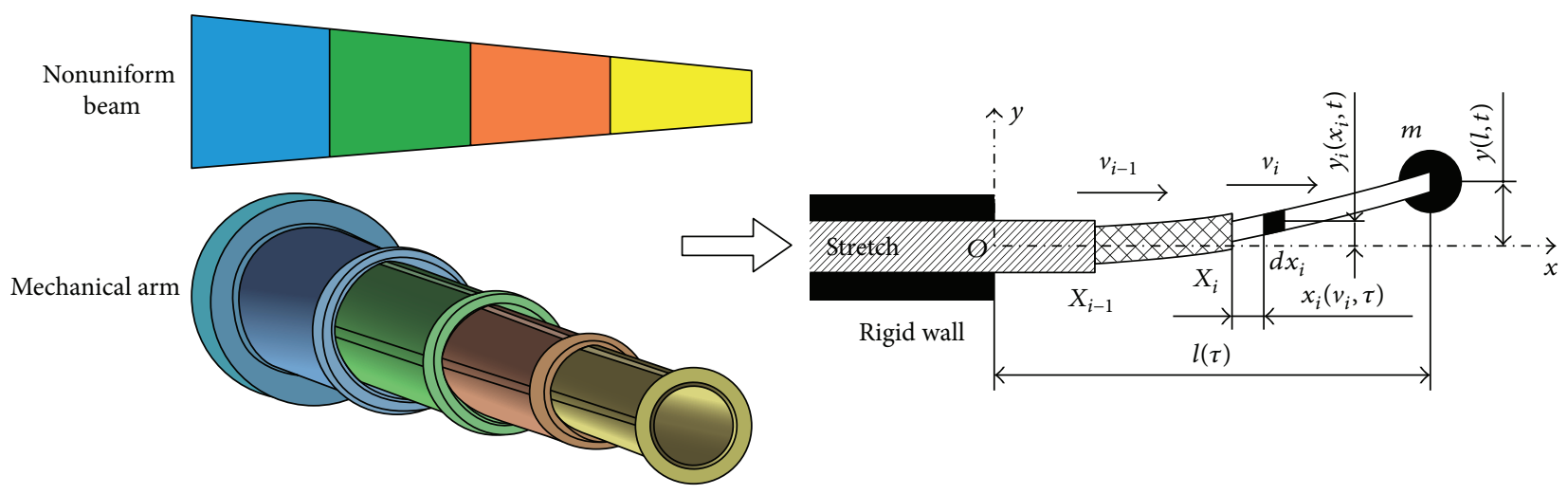

FIGURE 1: Axially moving stepped beam with different length and tip mass.

Mote Jr. [4] proposed a complex modal analysis procedure for axially moving materials, and the procedure could be used to determine the frequencies and the modal functions of moving string and beam. Stylianou and Tabarrok [5] used finite element method (FEM) to solve the dynamics problems of an axially moving uniform beam with variable length; they divided uniform beam into finite uniform elements. Öz and Pakdemirli [6] applied the method of multiple scales to solve the stability boundaries of an axially accelerating beam under pinned-pinned, clamped-clamped; and fixed supported conditions; respectively, where the time-dependent velocity is assumed to vary harmonically near a constant mean speed $v=v_{0}+\varepsilon v_{1} \sin (\Omega t)$. Ponomareva, Sandilo, and van Horssen $[7,8]$ concentrated on studying the transversal vibrations of continuum with time-varying velocity and variable length: transient from string to beam behaviour where the velocity is given by $v=\varepsilon\left(v_{0}+\alpha \sin (\Omega t)\right)$. In their papers, it is explicitly shown how to work with a combined model that is a string model at the low frequencies and a tensioned beam model at the higher frequencies. Ghayesh and Amabili [9] solved the steady-state transverse response of an axially moving beam with time-dependent axial speed $v=v_{0}+v_{1} \sin (\Omega t)$. Park et al. [10] investigated vibrations of an axially moving beam with deployment or retraction considering the actual application, where the speed is $v=d L(t) / d t$. Recently, Malookani and van Horssen investigated the resonances and the applicability of Galerkin's truncation method for an axially moving string with time-varying velocity [11]. Kazemirad et al. concentrated on thermal effects on nonlinear vibrations of an axially moving beam with an intermediate spring-mass support [12]. Furthermore, there are a lot of studies on axially moving Timoshenko and Viscoelastic beams [3, 13-17] and axially moving plates [18].

These beams above are almost homogeneous beams (strings); however, there are many nonuniform structures in engineering. In recent years, some scholars used analytical and numerical methods to investigate the nonuniform beam and made some progress in the research of stepped or variable cross section, heterogeneous beam. Gupta [19] used the FEM to calculate the frequency of variable cross section beam. This general method rapidly develops, while it has limitation such as complex computing process and long computing time. Lee and Ke [20] adopted analytical method to study the free vibration of nonuniform beam with general elastically retrained boundary conditions. Ece et al. [21] calculated the vibration characteristics of variable cross section rectangular beam. Leigh and Kunz [1] studied structural dynamics problems of multibody beam applying a mixed space time finite element scheme. Mao and Pietrzko [22] used Adomian decomposition method to investigate the vibration of stepped beam. Nevertheless, these objects above are static beams, and the dynamics problem of nonuniform beam has been analyzed without considering the axially moving effect. Some methods are not universally applicable, and the analytical method is complex and difficult to solve the nonuniform axially moving beam. It is well known that the axially moving nonuniform systems usually are modeled as stepped or segmental beams by some ways. If the transverse vibration continuously exists, this will obviously affect the stability and position accuracy of the slender members, which even can lead to the structure instability. Therefore, vibration analysis of stepped beam is important to consider the influence of moving axially for the dynamic design of the industrial transmission.

The remaining part of the paper is organized as follows. In Section 2, in consideration of the mature theory for uniform beam, stepped beam is divided into many segments with a view to obtain uniform beam. Every segment can be investigated as a uniform axially moving beam; then the frequency equation and the eigenvalue equation are derived by using analytical method. In Section 3, the characteristic and displacement of transverse free vibration can be calculated by using numerical method. This paper shows two examples and presents analysis and comparison to illustrate effect of velocity and mass on the vibration characteristics and displacement of AMSB. Finally, some concluding remarks are made in Section 4.

\section{Axially Moving Stepped Beam}

2.1. Free Vibration Equation. The cantilever structure which consisted of an AMSB with different length and tip mass is investigated as shown in Figure 1. The variable cross section beam (nonuniform beam) can be simplified as stepped beam. 
Considering a multibody stepped beam composed of several uniform segments, Euler-Bernoulli beam theories are used to model slender structures assuming that every beam is relatively thin compared to its length. There is segment $i$ ( $i=$ $1,2,3, \ldots, N)$ with mass per length $\rho_{i} S_{i}$, moment of inertial $I_{i}$, and the material stiffness $E_{i} I_{i}$. The beam undergoes the bending vibration described by the transverse displacement $y_{i}\left(x_{i}, t\right) ; x_{i}\left(v_{i}, \tau\right)$ is the axial coordinate, where $\tau$ and $t$ are the time. Every beam travels at axial transport speed $v_{i}(\tau)=$ $d l_{i}(\tau) / d \tau$ representing the variable speed of any segment $i$, where the length of one segment is $l_{i}(\tau)$. The tip constant mass $m$ lies in the right end of the variable length AMSB.

The kinetic energy and potential energy of the $i$ th segment and the $N$ th segment with a tip mass are

$$
\begin{aligned}
T= & \frac{1}{2} \int_{0}^{l_{i}} \rho_{i} S_{i} v_{i}^{2} d x_{i}+\frac{1}{2} \\
& \cdot \int_{0}^{l_{i}} \rho_{i} S_{i}\left(\frac{\partial y_{i}\left(x_{i}, t\right)}{\partial t}+v_{i} \frac{\partial y_{i}\left(x_{i}, t\right)}{\partial x_{i}}\right) d x_{i}, \\
T_{m} & =\frac{1}{2} \int_{0}^{l_{N}} \rho_{N} S_{N} v_{N}^{2} d x_{N}+\frac{1}{2} \\
& \cdot \int_{0}^{l_{N}} \rho_{N} S_{N}\left(\frac{\partial y_{N}\left(x_{N}, t\right)}{\partial t}+v_{N} \frac{\partial y_{N}\left(x_{N}, t\right)}{\partial x_{N}}\right) d x_{N} \\
& +\frac{1}{2} m v_{N}^{2}+\frac{1}{2}\left(\frac{D y_{N}\left(l_{N}, t\right)}{D t}\right)^{2}, \\
V= & \frac{1}{2} \int_{0}^{l_{i}} E_{i} I_{i}\left(\frac{\partial^{2} y_{i}\left(x_{i}, t\right)}{\partial x_{i}^{2}}\right)^{2} d x_{i} .
\end{aligned}
$$

A set of equations is presented by substitution of (1a), (1b), and (2) into Hamilton's principle:

$$
\begin{array}{r}
\delta\left[\int_{t_{1}}^{t_{2}}(T-V) d t\right]=0, \\
\delta\left[\int_{t_{1}}^{t_{2}}\left(T_{m}-V\right) d t\right]=0 .
\end{array}
$$

Setting the coefficients of $\delta y$ to zero yields the governing equation

$$
\begin{gathered}
\rho_{i} S_{i} \frac{\partial^{2} y_{i}\left(x_{i}, t\right)}{\partial t^{2}}+2 \rho_{i} S_{i} v_{i} \frac{\partial y_{i}\left(x_{i}, t\right)}{\partial x_{i} \partial t}+\rho_{i} S_{i} \dot{v}_{i} \frac{\partial y_{i}\left(x_{i}, t\right)}{\partial x} \\
+E_{i} I_{i} \frac{\partial^{4} y_{i}\left(x_{i}, t\right)}{\partial x^{4}}+\rho_{i} S_{i} v_{i}^{2} \frac{\partial^{2} y_{i}\left(x_{i}, t\right)}{\partial x^{2}}=0 .
\end{gathered}
$$

Assuming (4) does not include acceleration $\dot{v}$, it can be cast into the simplified form

$$
\rho_{i} S_{i} y_{i, t t}+2 \rho_{i} S_{i} v_{i} y_{i, x t}+\rho_{i} S_{i} v_{i}^{2} y_{i, x x}+E_{i} I_{i} y_{i, x x x x}=0 .
$$

Equation (5) defines a gyroscopic continuous system with complex eigenvalues. This solution of free vibration is assumed to be complex modal, so that the separable solution of (5) is

$$
\begin{aligned}
y_{i}\left(x_{i}, t\right) & =Y\left[\left(x_{i}\left(v_{i}, \tau\right), t\right)\right] \\
& =\sum_{n=1}^{n}\left[\phi_{i, n}\left(x_{i}\right) e^{i * \omega_{n} t}+\bar{\phi}_{i, n}\left(x_{i}\right) e^{-i * \omega_{n} t}\right], \\
x_{i}\left(v_{i}, \tau\right) & =x_{i 0}+v_{i} \tau .
\end{aligned}
$$

The inherent modal reflects vibration response under various external excitations, where the overbar denotes complex conjugation and $\omega_{n}$ and $\phi_{i, n}\left(x_{i}\right)(n=1,2,3, \ldots, M)$ are natural frequency and corresponding modal function. Then substitution of (6) into (5) yields eigenvalue equation

$$
\begin{aligned}
& -\rho_{i} S_{i} \omega^{2} \phi_{i, n}+2 i * \omega \rho_{i} S_{i} v_{i} \phi_{i, n}^{\prime}+\rho_{i} S_{i} v_{i}^{2} \phi_{i, n}^{\prime \prime}+E_{i} I_{i} \phi_{i, n}^{\prime \prime \prime \prime} \\
& =0 .
\end{aligned}
$$

The modal functions are determined by velocity, length, and tip mass. $\phi_{i, n}$ belonging to the segment $i$ can be solved from the homogeneous linear ordinary differential equation set; its form is set to

$$
\begin{aligned}
\phi_{i, n}\left(x_{i}\right)= & C_{i, 1} e^{i * \beta_{i, 1} x_{i}}+C_{i, 2} e^{i * \beta_{i, 2} x_{i}}+C_{i, 3} e^{i * \beta_{i, 3} x_{i}} \\
& +C_{i, 4} e^{i * \beta_{i, 4} x_{i}},
\end{aligned}
$$

where $C_{i, j}(j=1,2,3,4)$ are constants to be determined, $\beta_{i, j}(j=1,2,3,4)$ are four roots of the characteristic equation of $(8)$, and $x_{i}$ is the relative coordinate:

$$
x_{i}=x-X_{i}, \quad X_{i} \leq x \leq X_{i+1}, \quad(i=1,2,3, \ldots, N) .
$$

Substituting (9) (modal function) into (8), eigenvalue equation is expressed as

$$
E_{i} I_{i} \beta_{i, j}^{4}-\rho_{i} S_{i} v_{i}^{2} \beta_{i, j}^{2}-2 \omega_{n} \rho_{i} S_{i} v_{i} \beta_{i, j}-\rho_{i} S_{i} \omega_{n}^{2}=0 .
$$

Besides, there is another modal function $\phi_{i+1, n}\left(x_{i+1}\right)$ of the next segment $i+1$ :

$$
\begin{aligned}
\phi_{i+1, n}\left(x_{i+1}\right)= & C_{i+1,1} e^{i * \beta_{i+1,1} x_{i+1}}+C_{i+1,2} e^{i * \beta_{i+1,2} x_{i+1}} \\
& +C_{i+1,3} e^{i * \beta_{i+1,3} x_{i+1}}+C_{i+1,4} e^{i * \beta_{i+1,4} x_{i+1}},
\end{aligned}
$$

where $C_{i+1, j}(j=1,2,3,4)$ are also constants to be determined, $x_{i+1}$ is also the relative coordinate, and $\beta_{i+1, j}(j=$ $1,2,3,4)$ are four roots of the characteristic equation similar to (8) of segment $i+1$. Consider

$$
\begin{aligned}
& x_{i+1}=x-X_{i+1}, \\
& X_{i+1} \leq x \leq X_{i+2}, \quad(i=1,2,3, \ldots, N), \\
& E_{i+1} I_{i+1} \beta_{i+1, j}^{4}-\rho_{i+1} S_{i+1} v_{i+1}^{2} \beta_{i+1, j}^{2} \\
& -2 \omega_{n} \rho_{i+1} S_{i+1} v_{i+1} \beta_{i+1, j}-\rho_{i+1} S_{i+1} \omega_{n}^{2}=0 .
\end{aligned}
$$

The governing equation of next segment $i+1$ is just like (4) and (5); certainly, substitution of (12) into characteristic equation yields eigenvalue equation (14). 
2.2. Continuous Condition. The continuous condition is obtained by adopting the equal physical parameters at the connections between two segments of the AMSB; the relationship between the relative coordinates can be described as

$$
\begin{aligned}
x_{i} & =X_{i+1}-X_{i}=L_{i}\left(v_{i}, \tau\right), \\
x_{i+1} & =X_{i+1}-X_{i+1}=0, \\
L_{i}\left(v_{i}, \tau\right) & =L_{i 0}+v_{i} \tau .
\end{aligned}
$$

The transversal displacement, rotation, bending moment, and shear force are all equal for slender beam, so that continuous condition can be written as

$$
\begin{aligned}
y_{i}\left(L_{i}\right) & =y_{i+1}(0), \\
y_{i}^{\prime}\left(L_{i}\right) & =y_{i+1}^{\prime}(0), \\
E_{i} I_{i} y_{i}^{\prime \prime}\left(L_{i}\right) & =E_{i+1} I_{i+1} y_{i+1}^{\prime \prime}(0), \\
E_{i} I_{i} y_{i}^{\prime \prime \prime}\left(L_{i}\right) & =E_{i+1} I_{i+1} y_{i+1}^{\prime \prime \prime}(0),
\end{aligned}
$$

where $y_{i}^{(n)}(x, t)$ is the form of $(6), y_{i+1}^{(n)}(x, t)$ is a similar form like (6), and then substitution of the transverse displacement into (17) leads to

$$
\begin{aligned}
\phi_{i}\left(L_{i}\right) & =\phi_{i+1}(0), \\
\phi_{i}^{\prime}\left(L_{i}\right) & =\phi_{i+1}^{\prime}(0), \\
E_{i} I_{i} \phi_{i}^{\prime \prime}\left(L_{i}\right) & =E_{i+1} I_{i+1} \phi_{i+1}^{\prime \prime}(0), \\
E_{i} I_{i} \phi_{i}^{\prime \prime \prime}\left(L_{i}\right) & =E_{i+1} I_{i+1} \phi_{i+1}^{\prime \prime \prime}(0) .
\end{aligned}
$$

The two modal functions can give the mathematical relationship between $C_{1}$ and $C_{i+1}$. Substituting (9) and (12) into (18), a set of linear algebraic equations is given by

$$
Z_{i}\left(L_{i}\right) \cdot C_{i}=Z_{i+1}(0) \cdot C_{i+1} \cdot
$$

Equation (19) defines two matrices and four vectors that are applicable to any two segments of axially moving beam, where $C_{i}, C_{i+1}, Z_{i}$, and $Z_{i+1}$ are, respectively, defined as

$$
\begin{aligned}
C_{i}= & \left\{\begin{array}{llll}
C_{i, 1} & C_{i, 2} & C_{i, 3} & C_{i, 4}
\end{array}\right\}^{T}, \\
C_{i+1}= & \left\{\begin{array}{lllll}
C_{i+1,1} & C_{i+1,2} & C_{i+1,3} & C_{i+1,4}
\end{array}\right\}^{T}, \\
Z_{i}= & {\left[\begin{array}{cccc}
e^{i * L_{i} \beta_{i, 1}} & e^{i * L_{i} \beta_{i, 2}} & e^{i * L_{i} \beta_{i, 3}} & e^{i * L_{i} \beta_{i, 4}} \\
e^{i * L_{i} \beta_{i, 1}} \beta_{i, 1} & e^{i * L_{i} \beta_{i, 2}} \beta_{i, 2} & e^{i * L_{i} \beta_{i, 3}} \beta_{i, 3} & e^{i * L_{i} \beta_{i, 4}} \beta_{i, 4} \\
E_{i} I_{i} e^{i * L_{i} \beta_{i, 1}} \beta_{i, 1}^{2} & E_{i} I_{i} e^{i * L_{i} \beta_{i, 2}} \beta_{i, 2}^{2} & E_{i} I_{i} e^{i * L_{i} \beta_{i, 3}} \beta_{i, 3}^{2} & E_{i} I_{i} e^{i * L_{i} \beta_{i, 4}} \beta_{i, 4}^{2} \\
E_{i} I_{i} e^{i * L_{i} \beta_{i, 1}} \beta_{i, 1}^{3} & E_{i} I_{i} e^{i * L_{i} \beta_{i, 2}} \beta_{i, 2}^{3} & E_{i} I_{i} e^{i * L_{i} \beta_{i, 3}} \beta_{i, 3}^{3} & E_{i} I_{i} e^{i * L_{i} \beta_{i, 4}} \beta_{i, 4}^{3}
\end{array}\right], } \\
Z_{i+1}= & {\left[\begin{array}{cccc}
1 & 1 & 1 & 1 \\
\beta_{i+1,1} & \beta_{i+1,2} & \beta_{i+1,3} & \beta_{i+1,4} \\
E_{i+1} I_{i+1} \beta_{i+1,1}^{2} & E_{i+1} I_{i+1} \beta_{i+1,2}^{2} & E_{i+1} I_{i+1} \beta_{i+1,3}^{2} & E_{i+1} I_{i+1} \beta_{i+1,4}^{2} \\
E_{i+1} I_{i+1} \beta_{i+1,1}^{3} & E_{i+1} I_{i+1} \beta_{i+1,2}^{3} & E_{i+1} I_{i+1} \beta_{i+1,3}^{3} & E_{i+1} I_{i+1} \beta_{i+1,4}^{3}
\end{array}\right] . }
\end{aligned}
$$

The application for the whole stepped beam, the mathematical relationships between $C_{1}$ and $C_{N}$ that are the constant coefficients of modal functions, is summarized as follows:

$$
\begin{aligned}
& \left\{\begin{array}{l}
Z_{1}\left(L_{1}\right) \cdot C_{1}=Z_{2}(0) \cdot C_{2} \\
Z_{2}\left(L_{2}\right) \cdot C_{2}=Z_{3}(0) \cdot C_{3} \\
\vdots \\
Z_{N-1}\left(L_{N-1}\right) \cdot C_{N-1}=Z_{N}(0) \cdot C_{N}
\end{array}\right. \\
& \Longrightarrow\left\{\begin{array}{l}
Z_{2}^{-1}(0) \cdot Z_{1}\left(L_{1}\right) \cdot C_{1}=C_{2} \\
Z_{3}^{-1}(0) \cdot Z_{2}\left(L_{2}\right) \cdot C_{2}=C_{3} \\
\vdots \\
Z_{N}{ }^{-1}(0) \cdot Z_{N-1}\left(L_{N-1}\right) \cdot C_{N-1}=C_{N}
\end{array}\right.
\end{aligned}
$$

$$
\begin{aligned}
& Z_{N}{ }^{-1}(0) \cdot Z_{N-1}\left(L_{N-1}\right) \cdot Z_{N-1}(0)^{-1} \cdots \cdots Z_{1}\left(L_{1}\right) \\
& \quad \cdot C_{1}=C_{N} .
\end{aligned}
$$

Equation (22) is the continuous condition at the connections, whose expressions show an iterative method to calculate $C_{N}$ via $C_{1}$. In addition, continuous condition has no correlation with other boundary conditions such as fixed supported, simply supported, and hinged supported conditions.

2.3. Frequency Equation. The frequency equation is derived from boundary conditions. Considering the beam is fixed supported at one end, another end is free and has a tip mass. Setting the displacement, rotation, and bending moment to zero is equal to setting modal functions to zero at both ends; 
meanwhile, the shearing force is equal to inertial force. They lead to the following boundary conditions:

$$
\begin{aligned}
& y_{1}(0, t)=0, \\
& y_{1}^{\prime}(0, t)=0, \\
& y_{N}^{\prime \prime}\left(L_{N}, t\right)=0, \\
& E_{N} I_{N} y_{N}^{(3)}\left(L_{N}, t\right)=m \frac{D^{2} y_{N}\left(L_{N}, t\right)}{D t^{2}}, \\
& \frac{D^{2} y_{N}\left(L_{N}, t\right)}{D t^{2}}=\left(\frac{\partial^{2} y_{N}\left(L_{N}, t\right)}{\partial t^{2}}+2 v_{N} \frac{\partial^{2} y_{N}\left(L_{N}, t\right)}{\partial x_{N} \partial t}\right. \\
& \left.\quad+v_{N}^{2} \frac{\partial^{2} y_{N}\left(L_{N}, t\right)}{\partial x_{N}^{2}}\right) .
\end{aligned}
$$

Then, substituting (6), (9), and the transverse displacement and modal function of segment $N$ into (23), a set of linear algebraic equations is written as

$$
\begin{aligned}
& C_{1,1}+C_{1,2}+C_{1,3}+C_{1,4}=0, \\
& \beta_{1,1} C_{1,1}+\beta_{1,2} C_{1,2}+\beta_{1,3} C_{1,3}+\beta_{1,4} C_{1,4}=0, \\
& e^{i * L_{N} \beta_{N, 1}} \beta_{N, 1}^{2} C_{N, 1}+e^{i * L_{N} \beta_{N, 2}} \beta_{N, 2}^{2} C_{N, 2} \\
& \quad+e^{i * L_{N} \beta_{N, 3}} \beta_{N, 3}^{2} C_{N, 3}+e^{i * L_{N} \beta_{N, 4}} \beta_{N, 4}^{2} C_{N, 4}=0, \\
& C_{N, 1} s_{1} e^{i * \beta_{N, 1} L_{N}}+C_{N, 2} s_{2} e^{i * \beta_{N, 2} L_{N}}+C_{N, 3} s_{3} e^{i * \beta_{N, 3} L_{N}} \\
& \quad+C_{N, 4} s_{4} e^{i * \beta_{N, 4} L_{N}}=0, \\
& s_{1}=E_{N} I_{N} \beta_{N, 1}^{3}+i * m v_{N}^{2} \beta_{N, 1}^{2}+i * 2 m v_{N} \omega_{n} \beta_{N, 1} \\
& \quad+i * m \omega_{n}^{2}, \\
& s_{2}=E_{N} I_{N} \beta_{N, 2}^{3}+i * m v_{N}^{2} \beta_{N, 2}^{2}+i * 2 m v_{N} \omega_{n} \beta_{N, 2} \\
& \quad+i * m \omega_{n}^{2}, \\
& s_{3}=E_{N} I_{N} \beta_{N, 3}^{3}+i * m v_{N}^{2} \beta_{N, 3}^{2}+i * 2 m v_{N} \omega_{n} \beta_{N, 3} \\
& \quad+i * m \omega_{n}^{2}, \\
& s_{4}=E_{N} I_{N} \beta_{N, 4}^{3}+i * m v_{N}^{2} \beta_{N, 4}^{2}+i * 2 m v_{N} \omega_{n} \beta_{N, 4} \\
& \quad+i * m \omega_{n}^{2} .
\end{aligned}
$$

Define two matrices and two vectors to rewrite (25a) into (25d):

$$
\begin{aligned}
& C_{1}=\left\{\begin{array}{llll}
C_{1,1} & C_{1,2} & C_{1,3} & C_{1,4}
\end{array}\right\}^{T}, \\
& C_{N}=\left\{\begin{array}{llll}
C_{N, 1} & C_{N, 2} & C_{N, 3} & C_{N, 4}
\end{array}\right\}^{T},
\end{aligned}
$$

$$
\begin{aligned}
& B_{1}=\left[\begin{array}{cccc}
1 & 1 & 1 & 1 \\
\beta_{1,1} & \beta_{1,2} & \beta_{1,3} & \beta_{1,4}
\end{array}\right], \\
& B_{N} \\
& =\left[\begin{array}{cccc}
e^{i * L_{N} \beta_{N, 1}} \beta_{N, 1}^{2} & e^{i * L_{N} \beta_{N, 2}} \beta_{N, 2}^{2} & e^{i * L_{N} \beta_{N, 3}} \beta_{N, 3}^{2} & e^{i * L_{N} \beta_{N, 4}} \beta_{N, 4}^{2} \\
e^{i * L_{N} \beta_{N, 1}} s_{1} & e^{i * L_{N} \beta_{N, 2}} s_{2} & e^{i * L_{N} \beta_{N, 3} s_{3}} & e^{i * L_{N} \beta_{N, 4}} s_{4}
\end{array}\right] .
\end{aligned}
$$

Equations (25a) to (25d) can be cast into two sets of linear algebraic equations:

$$
\begin{gathered}
B_{1(2 \times 4)} \cdot C_{1}=0, \\
B_{N(2 \times 4)} \cdot C_{N}=0 .
\end{gathered}
$$

Equation (28a) is independent of (28b), but substitution of (22), just as the continuous condition between $C_{1}$ and $C_{N}$, into (28b) also gives a set of linear algebraic equations:

$$
\begin{gathered}
B_{N(2 \times 4)} \cdot\left[Z_{N}(0)\right]^{-1} \cdot Z_{N-1}\left(L_{N-1}\right) \cdot\left[Z_{N-1}(0)\right]^{-1} \cdots \\
\cdot Z_{1}\left(L_{1}\right) \cdot C_{1}=0 .
\end{gathered}
$$

Combining (28a) and (29) gives another form of boundary conditions

$$
\begin{aligned}
& {\left[\begin{array}{c}
B_{1(2 \times 4)} \\
B_{N(2 \times 4)} \cdot\left[Z_{N}(0)\right]^{-1} \cdot Z_{N-1}\left(L_{N-1}\right) \cdot\left[Z_{N-1}(0)\right]^{-1} \cdots \cdot Z_{1}\left(L_{1}\right)
\end{array}\right]} \\
& \cdot C_{1}=B_{4 \times 4} \cdot C_{1}=0 .
\end{aligned}
$$

Nontriviality of solutions to homogeneous equation (30) requires its determinant of coefficients to be zero; the frequency equation of stepped beam with several different segments is given as

$$
\operatorname{det}\left[B_{4 \times 4}\right]=0 .
$$

The solution to (6) is segmental and feasible in the case of $L_{i}$ being equal or unequal:

$$
\begin{aligned}
& y(x, t) \\
& =\left\{y_{1}\left(x_{1}, t\right), \ldots, y_{n}\left(x_{n}, t\right)\right\}^{T} \\
& = \begin{cases}\sum_{n=1}^{n}\left[\phi_{1, n}\left(x_{1}\right) e^{i * \omega_{n} t}+\bar{\phi}_{1, n}\left(x_{1}\right) e^{-i * \omega_{n} t}\right], \quad\left(0<x_{1}<l_{1}\right), \\
\vdots \\
\sum_{n=1}^{n}\left[\phi_{1, n}\left(x_{n}\right) e^{i * \omega_{n} t}+\bar{\phi}_{1, n}\left(x_{n}\right) e^{-i * \omega_{n} t}\right], & \left(l_{n-1}<x_{n}<l_{n}\right) .\end{cases}
\end{aligned}
$$

The frequency equation and the eigenvalue equation have been given. According to the four roots of algebraic equations (11) and (14) and so on, as soon as they satisfy frequency equation (31), the natural frequency of the AMSB can be found. Because the coefficient $C_{1}$ of (30) is of linear correlation, substitution of the four roots into the assumed modal function obtains the true modal function of one segment. Finally, the next modal function is solved by the continuous condition; combining all the modal functions gives the whole modal function. 
TABLE 1: Three models of AMSB.

\begin{tabular}{|c|c|c|c|c|c|c|c|c|}
\hline \multicolumn{3}{|c|}{ Case 1} & \multicolumn{3}{|c|}{ Case 2} & \multicolumn{3}{|c|}{ Case 3} \\
\hline $\begin{array}{l}d_{1}=0.1 \mathrm{~m} \\
d_{2}=0.1 \mathrm{~m}\end{array}$ & $\begin{array}{l}l_{1}\left(t_{0}\right)=2.5 \mathrm{~m} \\
l_{2}\left(t_{0}\right)=2.5 \mathrm{~m}\end{array}$ & $\begin{array}{l}v_{1}=v_{2} \\
v_{1}<v_{2}\end{array}$ & $\begin{array}{l}d_{1}=0.15 \mathrm{~m} \\
d_{2}=0.1 \mathrm{~m}\end{array}$ & $\begin{array}{l}l_{1}\left(t_{0}\right)=2.5 \mathrm{~m} \\
l_{2}\left(t_{0}\right)=2.5 \mathrm{~m}\end{array}$ & $v_{1}=v_{2}$ & $\begin{aligned} d_{1} & =0.15 \mathrm{~m} \\
d_{2} & =0.1 \mathrm{~m}\end{aligned}$ & $\begin{array}{l}l_{1}\left(t_{0}\right)=1 \mathrm{~m} \\
l_{2}\left(t_{0}\right)=4 \mathrm{~m}\end{array}$ & $v_{1}=v_{2}$ \\
\hline
\end{tabular}

2.4. Hilbert Transform and Enveloping Line. The solution of free vibration equation (32) is just like a complex form, which has a real part and an imaginary part. At the same time, the solution is solved by using modal superposition method, and its curve exhibits a form of harmonic solution because of modal truncation. Now, enveloping line of the curve can be obtained by adopting Hilbert transform. The real part or imaginary part is rewritten as

$$
y_{n}\left(x_{n}, t\right)=x_{m}(t)+j * \widehat{x}_{m}(t),
$$

where $j^{*}$ is the imaginary unit and the enveloping line of the curve is

$$
\eta_{n}(t)=\left|y_{n}\left(x_{n}, t\right)\right|=\sqrt{x_{n}^{2}(t)+j * \widehat{x}_{n}^{2}(t)}
$$

where imaginary part is Hilbert transform solved by applying FFT (Fast Fourier Transform)

$$
\widehat{x}_{n}(t)=H\left[x_{n}(t)\right]=\frac{1}{\pi} \int_{-\infty}^{\infty} \frac{x_{n}(\tau)}{t-\tau} d \tau .
$$

2.5. Other Boundary Conditions. If the boundary conditions are simply supported and fixed supported, substitution of the values for modal function at both ends into boundary conditions can also give the homogeneous linear equations. Then the natural frequency and modal function can be calculated as above.

The simply supported condition is given by

$$
\begin{array}{r}
y_{1}(0, t)=0 ; \\
y_{1}^{\prime \prime}(0, t)=0 ; \\
y_{N}\left(L_{N}, t\right)=0 ; \\
y_{N}^{\prime \prime}\left(L_{N}, t\right)=0 .
\end{array}
$$

The fixed supported condition is given by

$$
\begin{array}{r}
y_{1}(0, t)=0 ; \\
y_{1}^{\prime}(0, t)=0 ; \\
y_{N}\left(L_{N}, t\right)=0 ; \\
y_{N}^{\prime}\left(L_{N}, t\right)=0 .
\end{array}
$$

The boundary condition of tip mass is given by

$$
E_{i} I_{i} y_{i}^{(3)}\left(x_{i}, t\right)=m \frac{D y_{i}^{2}\left(x_{i}, t\right)}{D^{2} t} .
$$

As is known to all, scholars usually use vibration equation of dimensionless forms to investigate the vibration of axially moving beam in a lot of references. Supposing that all the equations above are dimensionless forms, the variable $x_{i}$ or $x_{i+1}$ of each modal function is from 0 to 1 . If the beam has multiple unequal segments, continuous condition can also be applied to connections of all the segments.

\section{Numerical Example}

3.1. Simplified Model-Uniform Beam. The AMSB is composed of one segment, which is of the variable length and velocity. The material of the beam is carbon fiber widely used in aerospace and other industrial fields. Obviously, the beam is a homogeneous cantilever beam. The boundary conditions include cantilever and tip mass. This uniform beam, with density $\rho_{1}=1.81 \times 10^{3} \mathrm{~kg} / \mathrm{m}^{3}$, diameter $d_{1}=0.1 \mathrm{~m}$, length $l_{1}\left(t_{0}\right)=5 \mathrm{~m}$, and Young's modulus $E_{1}=2.94 \times 10^{11} \mathrm{~Pa}$, travels at speed $v_{1}$; the tip mass is $5 \mathrm{~kg}$ or $25 \mathrm{~kg}$. From (10), (28a), and (28b), infinite characteristic roots $\beta_{j, n}$ and natural frequencies $f_{n}(\mathrm{~Hz})$ can be numerically solved via an available routine for linear equations.

Figure 2(a) shows that the natural frequency decreases with increasing speed; Figure 2(b) shows that the 2nd natural frequency decreases with increasing time in the case of different masses. When the uniform beam travels at a low speed like $v \leqslant 10 \mathrm{~m} / \mathrm{s}$, substituting the roots $\beta_{j}$ into modal function after the natural frequency is determined by the eigenvalues and frequency equations; the complex modal function shown in Figure 2(c) is obtained. Figure 2(d) shows the tip displacement calculated by using modal superposition method. Generally speaking, the value of the coefficient $C_{i, 1}$ depends on the initial conditions $[4,11]$, but, in this paper, the coefficient $C_{i, 1}$ is assumed to be 1 in order to simplify the modal functions. The vibration characteristics and displacement decrease as the tip mass increases; at the same time modal function is affected by the tip mass. Figures 2(e) and 2(f) shows different modal functions at different speeds $v=1 \sim 100 \mathrm{~m} / \mathrm{s}$ and times $t=0 \sim 1 \mathrm{~s}, l(t)=5 \sim 6 \mathrm{~m}$; it is clear that modal functions become irregular with the increase of speed like $v>10 \mathrm{~m} / \mathrm{s}$ and longer with the increase of time.

3.2. Multiple Segments Model. Now the AMSB is divided into two segments. The material of the every segment is carbon fiber, which is a homogeneous beam. The two segments have the same density $\rho_{1}=\rho_{2}=1.81 \times 10^{3} \mathrm{~kg} / \mathrm{m}^{3}$ and Young's modulus $E_{1}=E_{2}=2.94 \times 10^{11} \mathrm{~Pa}$; the diameters $d_{1}, d_{2}$ and lengths $l_{1}, l_{2}$ are shown in Table 1 . The initial total length adds up to 5 meters long, which is the same as Section 3.1. The beam travels at same or different axial transport speeds $v_{i}, v_{i+1}$, and the tip mass is $5 \mathrm{~kg}$ or $25 \mathrm{~kg}$. 

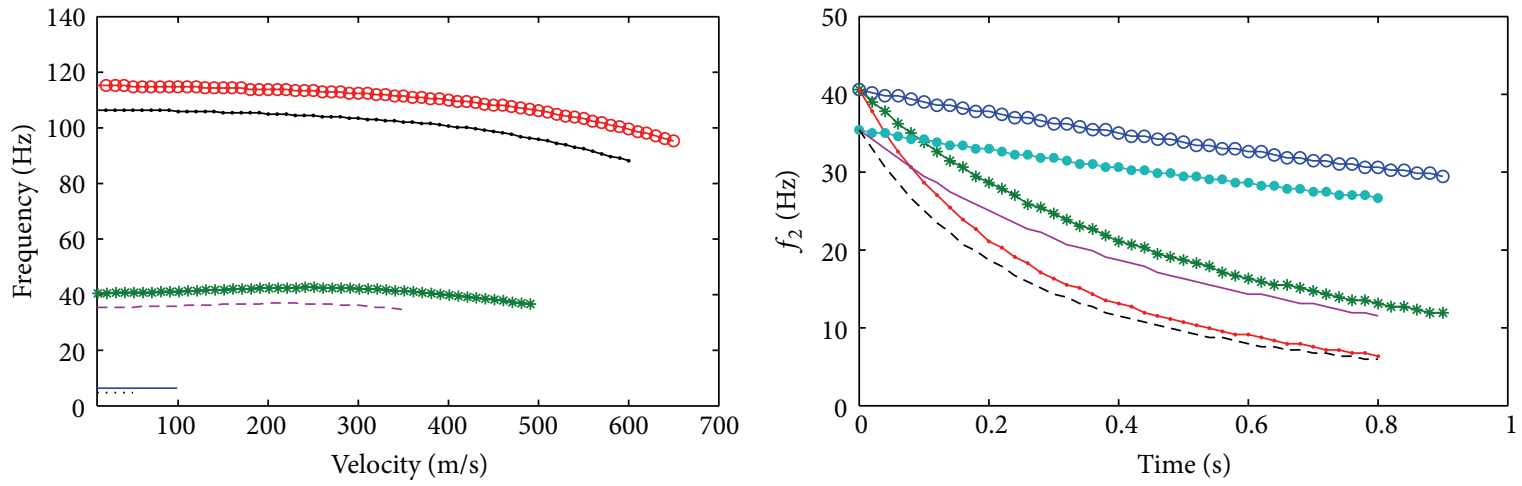

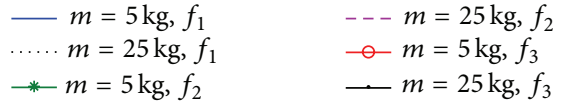

(a)
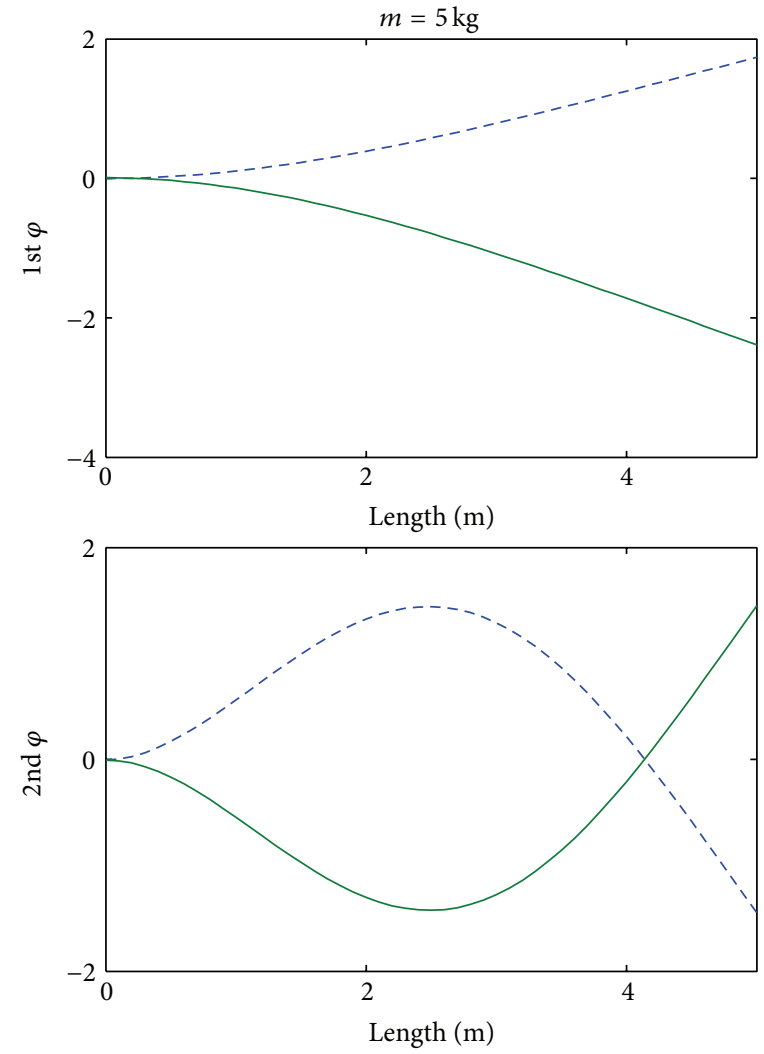

$$
\text { --- Im }
$$$$
\text { - Re }
$$
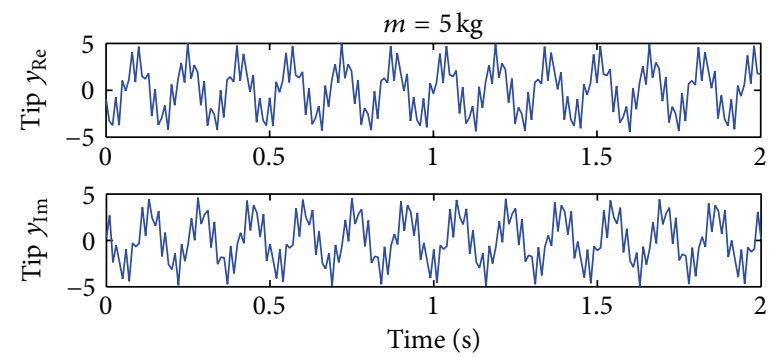

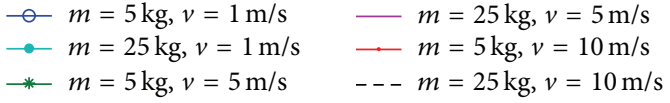

(b)
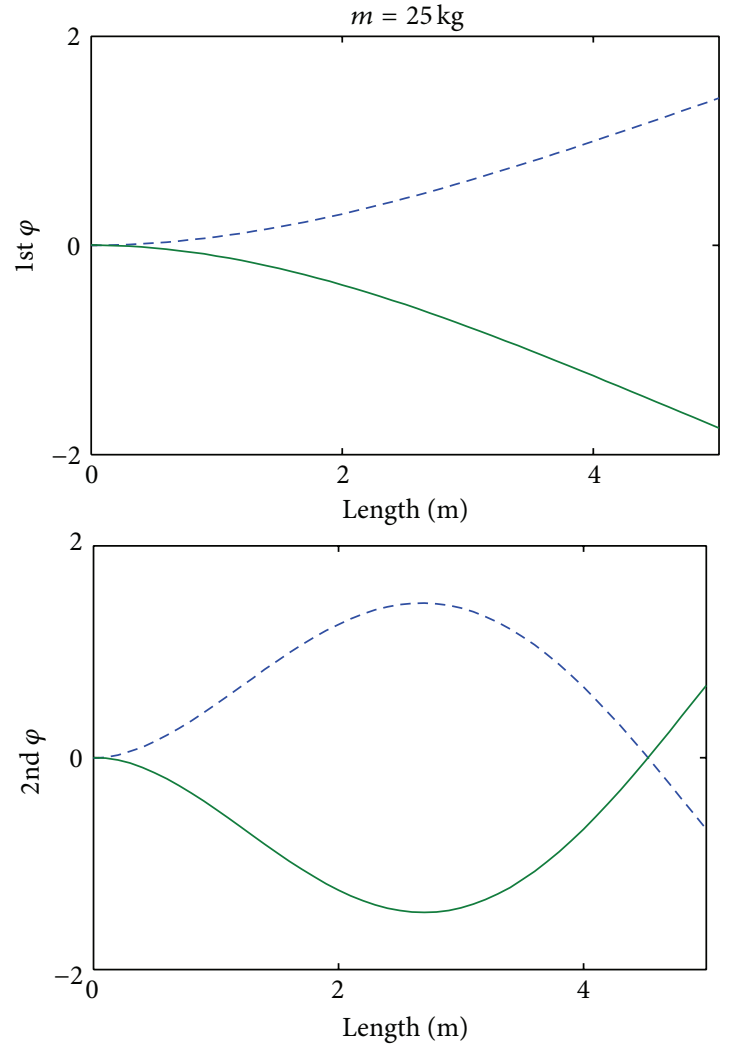

- - - Im

)

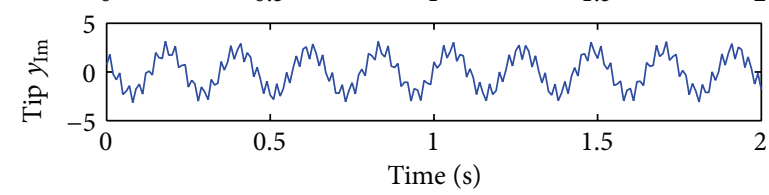

(d)

Figure 2: Continued. 

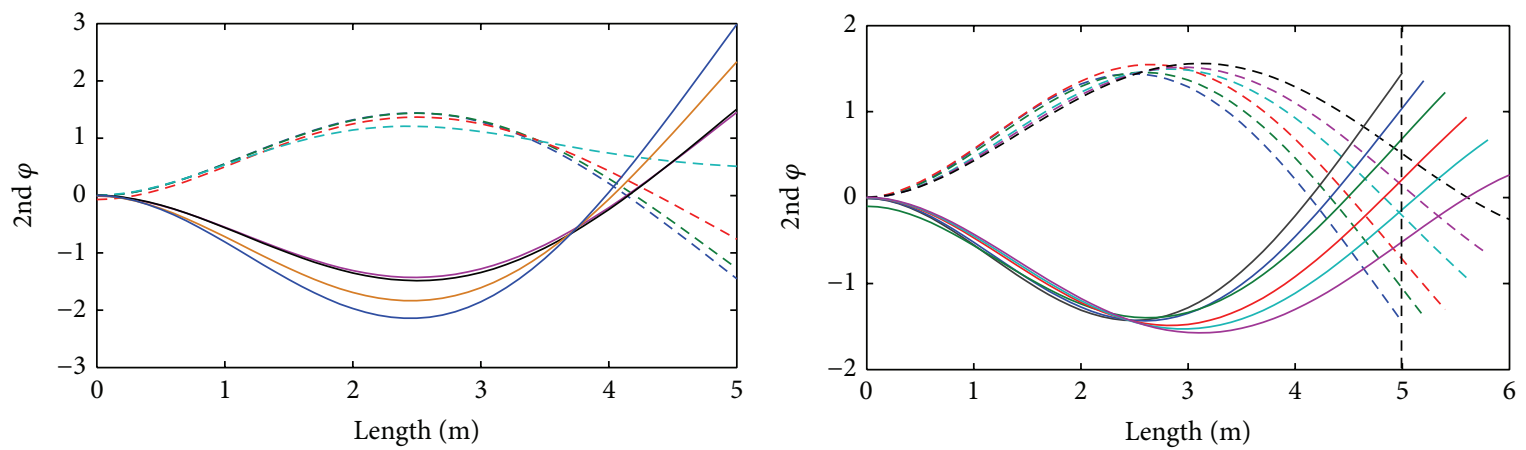

$$
\begin{aligned}
& \operatorname{Im} \\
& ---v=1 \mathrm{~m} / \mathrm{s} \\
& ---v=10 \mathrm{~m} / \mathrm{s} \\
& ---v=50 \mathrm{~m} / \mathrm{s} \\
& ---v=100 \mathrm{~m} / \mathrm{s}
\end{aligned}
$$

$$
\begin{aligned}
& \operatorname{Re} \\
& \square v=1 \mathrm{~m} / \mathrm{s} \\
&-v=10 \mathrm{~m} / \mathrm{s} \\
&-v=50 \mathrm{~m} / \mathrm{s} \\
& \square=100 \mathrm{~m} / \mathrm{s}
\end{aligned}
$$

\begin{tabular}{|c|c|c|c|c|c|}
\hline \multicolumn{2}{|c|}{ Parameters } & $f_{1} / \mathrm{Hz}$ & $f_{2} / \mathrm{Hz}$ & $f_{3} / \mathrm{Hz}$ & $f_{3} / \mathrm{Hz}, v=300 \mathrm{~m} / \mathrm{s}$ \\
\hline \multirow{3}{*}{2 segments' beam } & $v=10 \mathrm{~m} / \mathrm{s}, m=0$ & 7.32 & 45.22 & 125.8 & 123.4 \\
\hline & $v=10 \mathrm{~m} / \mathrm{s}, m=5 \mathrm{~kg}$ & 6.37 & 40.45 & 115.4 & 112.3 \\
\hline & $v=10 \mathrm{~m} / \mathrm{s}, m=25 \mathrm{~kg}$ & 4.62 & 35.35 & 106.7 & 103.5 \\
\hline \multirow{3}{*}{ Uniform beam } & $v=10 \mathrm{~m} / \mathrm{s}, m=0$ & 7.18 & 44.68 & 125 & 122.3 \\
\hline & $v=10 \mathrm{~m} / \mathrm{s}, m=5 \mathrm{~kg}$ & 6.37 & 40.45 & 115.3 & 112.4 \\
\hline & $v=10 \mathrm{~m} / \mathrm{s}, m=25 \mathrm{~kg}$ & 4.78 & 35.43 & 106.4 & 103.5 \\
\hline
\end{tabular}

(e)

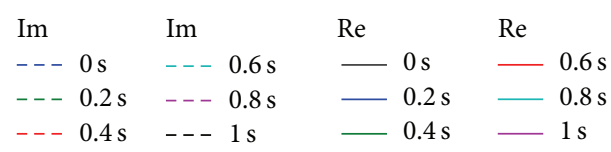

(f)

FIGURE 2: (a) Natural frequency changes with velocity. (b) Natural frequency changes with time. (c) $v=10 \mathrm{~m} / \mathrm{s}$, the modal function changes. (d) $v=10 \mathrm{~m} / \mathrm{s}$, the tip displacement changes. (e) $m=5 \mathrm{~kg}$, the modal function changes with velocity. (f) $m=5 \mathrm{~kg}, v=1 \mathrm{~m} / \mathrm{s}$, the modal function changes with different length.

TABLE 2: Comparison of frequency for three methods.

According to the continuous condition and frequency equation, the nature frequency of the AMSB can be calculated by using numerical method. When the beam travels at a low speed like $v=10 \mathrm{~m} / \mathrm{s}$ as well, substitution of the roots $\beta_{j, n}$ into each modal function obtains the whole complex modal function whose real and imaginary curve are painted.

Figures 3(a) and 3(b) show that the natural frequency of two segments' beam varies with velocity and time, and the modal function corresponding to each order frequency is different and continuous. It is well known that the continuous condition is available at every connection; in that way the integral modal function must be continuous as shown in Figure 3(c). Because the frequency changes with velocity continuously, the complex modal function corresponding to each order natural frequency is continuous at any speed as well. When the segmental beam's length and diameter are not the same, the modal function is still continuous at every connection. Figure 3(d) shows the tip displacements after Hilbert transform in the case of different masses; the values in two figures decrease as the tip mass increases.

Figure 4(a) shows that the second-order natural frequency of two segments' beam decreases with different speeds as the time increases, and Figure 4(b) shows the comparison of three cases in Table 1 and that the second-order natural frequency with different dimensions decreases as the speed increases.

3.3. Comparison. The finite element software cannot calculate the inherent characteristics of movement structures, though there is comparison of the semianalytical method above. The inherent characteristics of AMSB contrast the ones of beam without tip mass traveling at speed like $v=$ $10 \mathrm{~m} / \mathrm{s}$, or $300 \mathrm{~m} / \mathrm{s}$. The natural frequencies are compared as shown in Table 2.

This frequency is close to the one of example 1 from Table 2; for example, when $v=10 \mathrm{~m} / \mathrm{s}, m=5 \mathrm{~kg}$ and $25 \mathrm{~kg}$, the $2 \mathrm{nd}$ frequency is $40.45 \mathrm{~Hz}, 35.43 \mathrm{~Hz}$, and when $m=25 \mathrm{~kg}$, $v=10 \mathrm{~m} / \mathrm{s}$ and $300 \mathrm{~m} / \mathrm{s}$, the 2nd frequency is $106.7 \mathrm{~Hz}$, $103.5 \mathrm{~Hz}$. The greater the mass and velocity, the smaller the amplitude. The 1st and 2nd modal functions are continuous and similar according to Figures 2 and 3. These facts show that this method used to solve the vibration problem is available.

\section{Conclusion}

In this work, based on the Euler-Bernoulli beam theory, the transverse free vibration of the AMSB with different length 

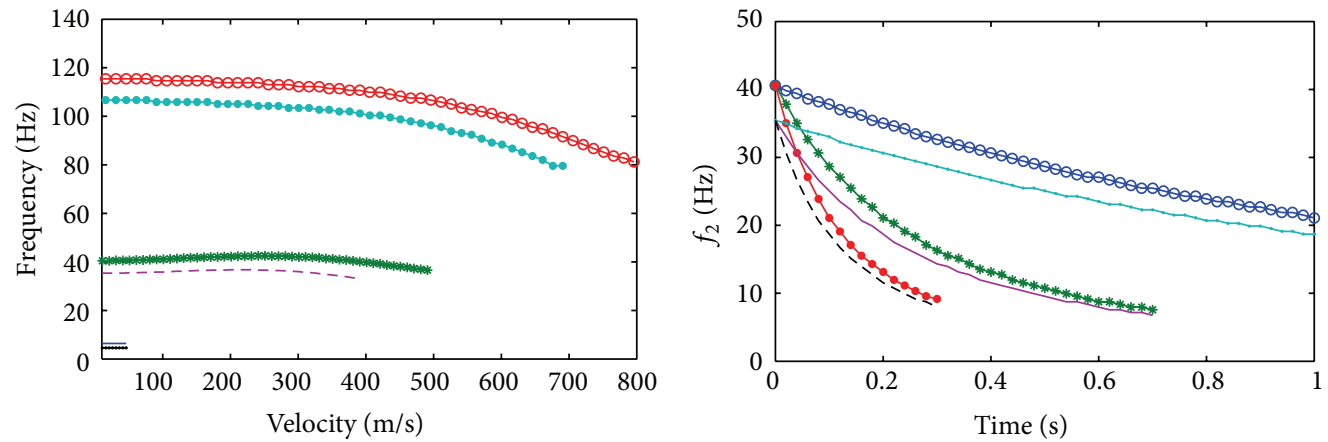

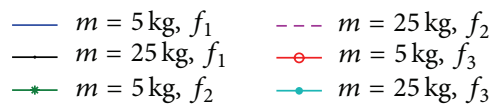

(a)
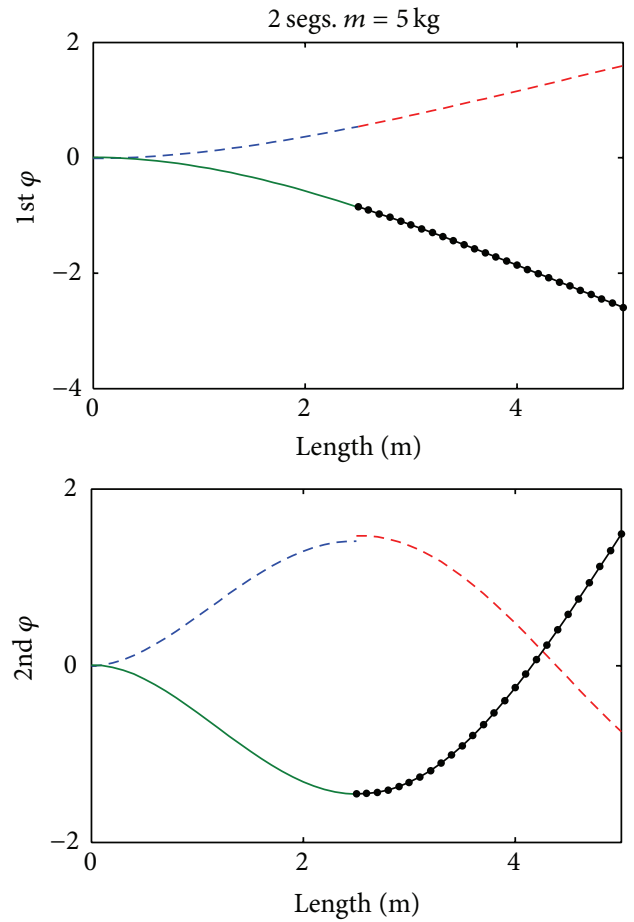

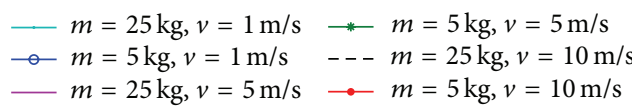

(b)
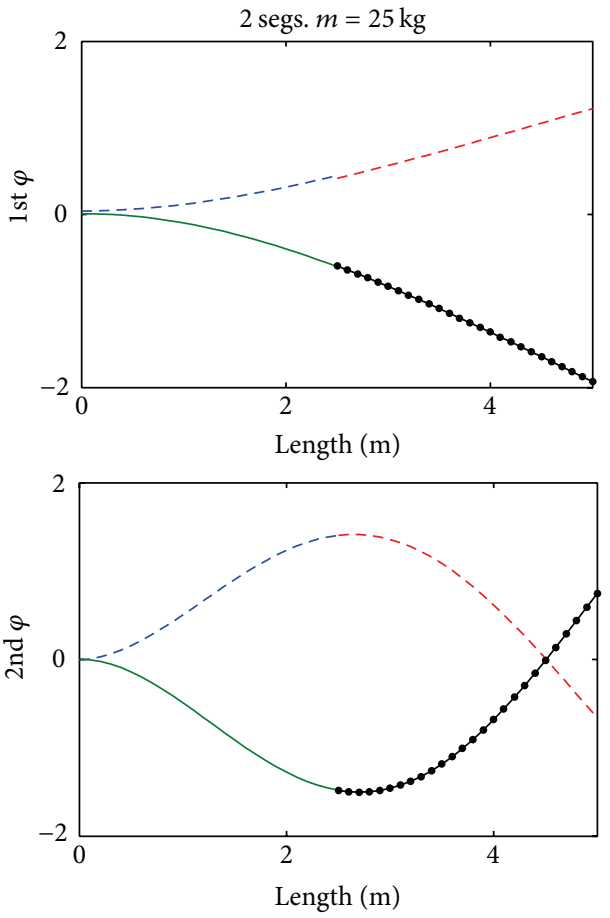

$---1 \mathrm{Im}$

-- $2 \mathrm{Im}$

$--2 \mathrm{Im}$

$-1 \mathrm{Re}$

$\rightarrow 2 \mathrm{Re}$

(c)
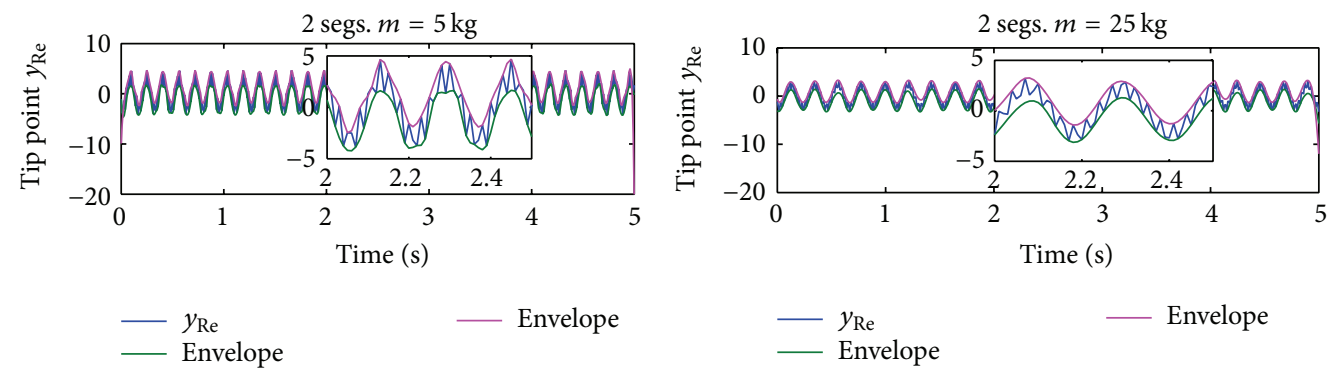

- Envelope

$y_{\operatorname{Re}}$
- Envelope

_ Envelope

(d)

FIGURE 3: (a) Natural frequency changes with velocity. (b) Natural frequency changes with time. (c) $v=10 \mathrm{~m} / \mathrm{s}$ the modal function changes. (d) $v=10 \mathrm{~m} / \mathrm{s}$, the tip displacement $y_{\mathrm{Re}}$ changes. 


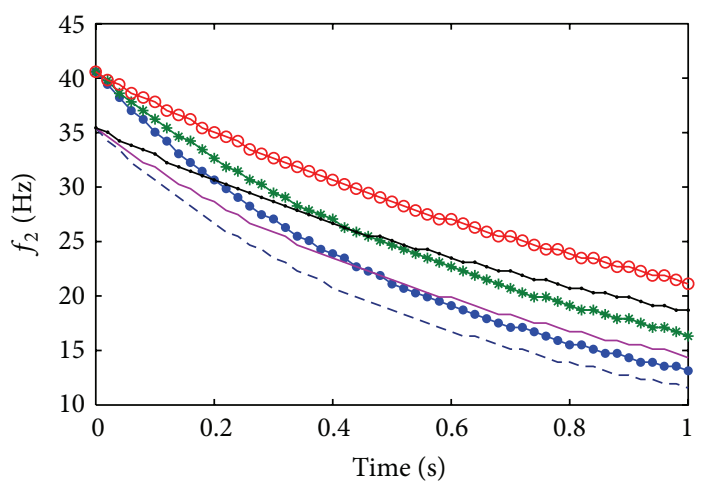

$$
\begin{array}{ll}
m=5 \mathrm{~kg}, v_{1}=1 \mathrm{~m} / \mathrm{s} & m=25 \mathrm{~kg}, v_{1}=1 \mathrm{~m} / \mathrm{s} \\
\rightarrow-v_{2}=1 \mathrm{~m} / \mathrm{s} & --v_{2}=1 \mathrm{~m} / \mathrm{s} \\
\rightarrow-v_{2}=2 \mathrm{~m} / \mathrm{s} & -v_{2}=2 \mathrm{~m} / \mathrm{s} \\
-v_{2}=3 \mathrm{~m} / \mathrm{s} & -v_{2}=3 \mathrm{~m} / \mathrm{s}
\end{array}
$$

(a)

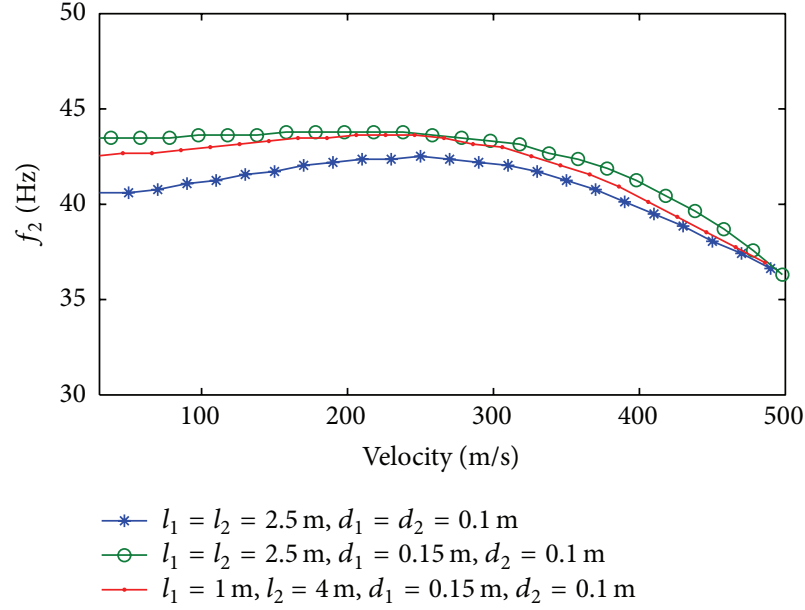

(b)

Figure 4: (a) Different $v, 2$ same segments, $f_{2}$; (b) different $L, S, 2$ segments, $m=5 \mathrm{~kg}, f_{2}$.

and tip mass is investigated. The semianalytical method is used to investigate the computation of vibration characteristics and displacement of the cantilever structure above, which are deduced through complex modal analysis and modal superposition, calculated by using numerical method and Hilbert transform, respectively. The first numerical example of uniform beam reveals that the natural frequencies decrease with increasing speed and tip mass $m=5 \mathrm{~kg}$ or $25 \mathrm{~kg}$; the modal function changes with velocity and tip mass, which presents bending modal at low speed like $v \leqslant 10 \mathrm{~m} / \mathrm{s}$ and irregular bending modal at high speed like $v \geqslant 50 \mathrm{~m} / \mathrm{s}$. What is more, the modal function divides into the real part and the imaginary part, both of which are approximately symmetric at low speed. The second numerical example calculates equal frequencies, modal functions, and displacements which have the same certain laws as the first ones; besides, the segmental modal functions are continuous at the connections, and the displacements after Hilbert transform display cycles obviously. The two numerical examples illustrate that velocities and tip masses affect vibration significantly. Therefore, this method actually has effect on calculating the frequency, modal function, and displacement of this object.

\section{Conflict of Interests}

The authors declare that there is no conflict of interests regarding the publication of this paper.

\section{References}

[1] E. J. Leigh and D. L. Kunz, "Simulation of a moving elastic beam using Hamilton's weak principle," AIAA Journal, vol. 45, no. 2, pp. 471-476, 2007.

[2] C. D. Mote Jr., "A study of band saw vibrations," Journal of the Franklin Institute, vol. 279, no. 6, pp. 430-444, 1965.
[3] A. Simpson, "Transverse modes and frequencies of beams translating between fixed and supports," Journal of Mechanical Engineering Science, vol. 15, no. 3, pp. 159-164, 1973.

[4] J. A. Wickert and C. D. Mote Jr., "Classical vibration analysis of axially moving continua," Journal of Applied Mechanics, vol. 57, no. 3, pp. 738-744, 1990.

[5] M. Stylianou and B. Tabarrok, "Finite element analysis of an axially moving beam, part I: time integration," Journal of Sound and Vibration, vol. 178, no. 4, pp. 433-453, 1994.

[6] H. R. Öz and M. Pakdemirli, "Vibrations of an axially moving beam with time-dependent velocity," Journal of Sound and Vibration, vol. 227, no. 2, pp. 239-257, 1999.

[7] S. V. Ponomareva and W. T. van Horssen, "On the transversal vibrations of an axially moving continuum with a time-varying velocity: transient from string to beam behavior," Journal of Sound and Vibration, vol. 325, no. 4-5, pp. 959-973, 2009.

[8] S. H. Sandilo and W. T. van Horssen, "On boundary damping for an axially moving beam and on the variable length induced vibrations of an elevator cable," in Proceedings of the 7th European Nonlinear Oscillations Conference, pp. 24-29, Rome, Italy, July 2011.

[9] M. H. Ghayesh and M. Amabili, "Steady-state transverse response of an axially moving beam with time-dependent axial speed," International Journal of Non-Linear Mechanics, vol. 49, pp. 40-49, 2013.

[10] S. Park, H. H. Yoo, and J. Chung, "Vibrations of an axially moving beam with deployment or retraction," AIAA Journal, vol. 51, no. 3, pp. 686-696, 2013.

[11] R. A. Malookani and W. T. van Horssen, "On resonances and the applicability of Galerkin's truncation method for an axially moving string with time-varying velocity," Journal of Sound and Vibration, vol. 344, pp. 1-17, 2015.

[12] S. Kazemirad, M. H. Ghayesh, and M. Amabili, "Thermal effects on nonlinear vibrations of an axially moving beam with an intermediate spring-mass support," Shock and Vibration, vol. 20, no. 3, pp. 385-399, 2013.

[13] H. Oh, J. Kim, and U. Lee, "Spectral element model for the vibration of an axially moving timoshenko beam," in 
Proceedings of the 44th AIAA/ASME/ASCE/AHS/ASC Structures, Structural Dynamics, and Materials Conference, AIAA-20031692, Norfolk, Va, USA, April 2003.

[14] M. H. Ghayesh and M. Amabili, "Three-dimensional nonlinear planar dynamics of an axially moving Timoshenko beam," Archive of Applied Mechanics, vol. 83, no. 4, pp. 591-604, 2013.

[15] H. Ding and L.-Q. Chen, "Nonlinear models for transverse forced vibration of axially moving viscoelastic beams," Shock and Vibration, vol. 18, no. 1-2, pp. 281-287, 2011.

[16] L.-Q. Chen, H. Ding, and C. W. Lim, "Principal parametric resonance of axially accelerating viscoelastic beams: multi-scale analysis and differential quadrature verification," Shock and Vibration, vol. 19, no. 4, pp. 527-543, 2012.

[17] H. Lv, Y. Li, L. Li, and Q. Liu, "Transverse vibration of viscoelastic sandwich beam with time-dependent axial tension and axially varying moving velocity," Applied Mathematical Modelling, vol. 38, no. 9-10, pp. 2558-2585, 2014.

[18] K. Marynowski and T. Kapitaniak, "Dynamics of axially moving continua," International Journal of Mechanical Sciences, vol. 81, pp. 26-41, 2014.

[19] A. K. Gupta, "Vibration of tapered beams," Journal of Structural Engineering, vol. 111, no. 1, pp. 19-36, 1985.

[20] S. Y. Lee and H. Y. Ke, "Free vibrations of a non-uniform beam with general elastically restrained boundary conditions," Journal of Sound and Vibration, vol. 136, no. 3, pp. 425-437, 1990.

[21] M. C. Ece, M. Aydogdu, and V. Taskin, "Vibration of a variable cross-section beam," Mechanics Research Communications, vol. 34, no. 1, pp. 78-84, 2007.

[22] Q. Mao and S. Pietrzko, "Free vibration analysis of stepped beams by using Adomian decomposition method," Applied Mathematics and Computation, vol. 217, no. 7, pp. 3429-3441, 2010. 

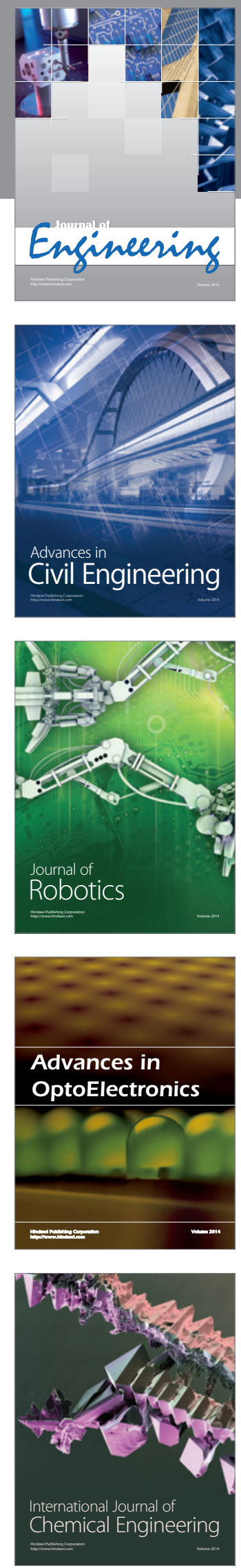

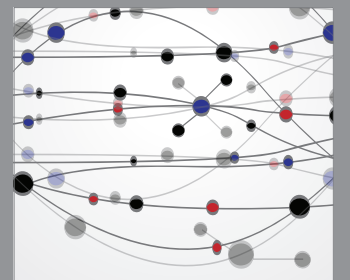

The Scientific World Journal
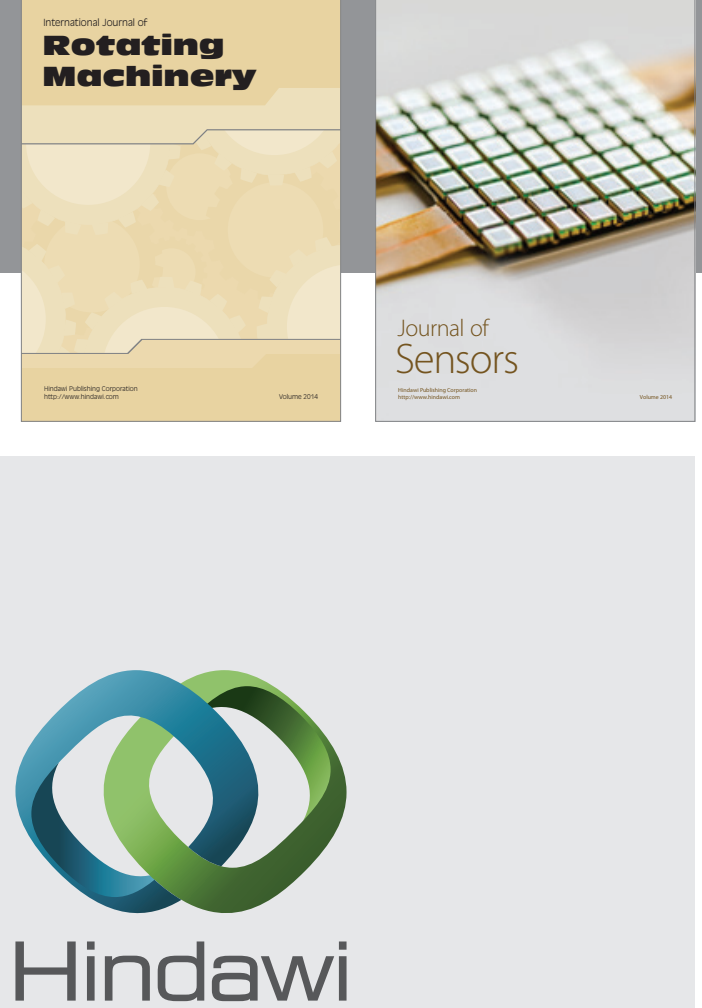

Submit your manuscripts at http://www.hindawi.com
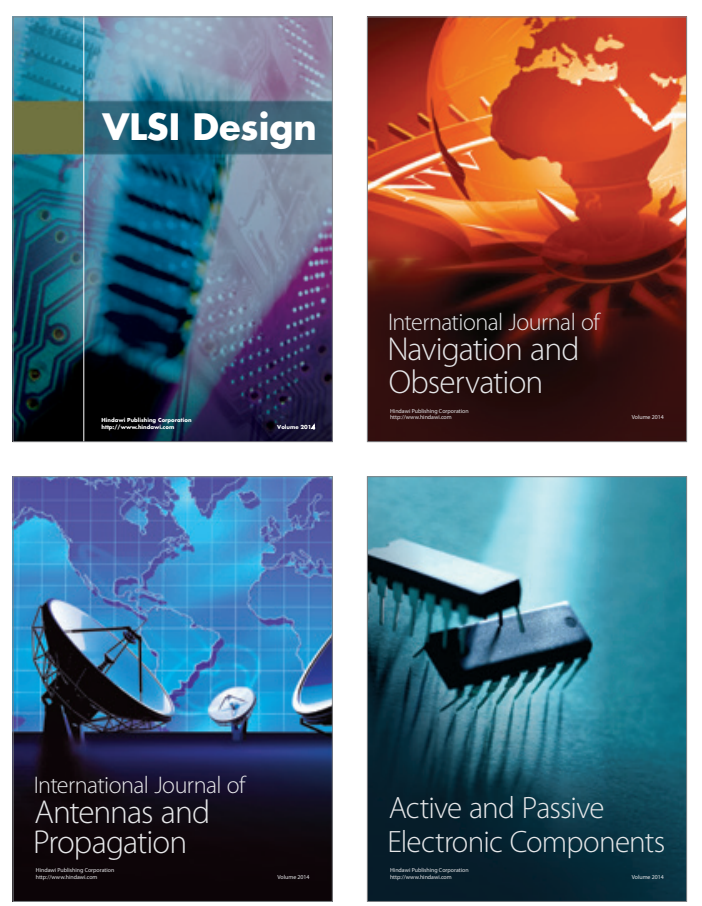
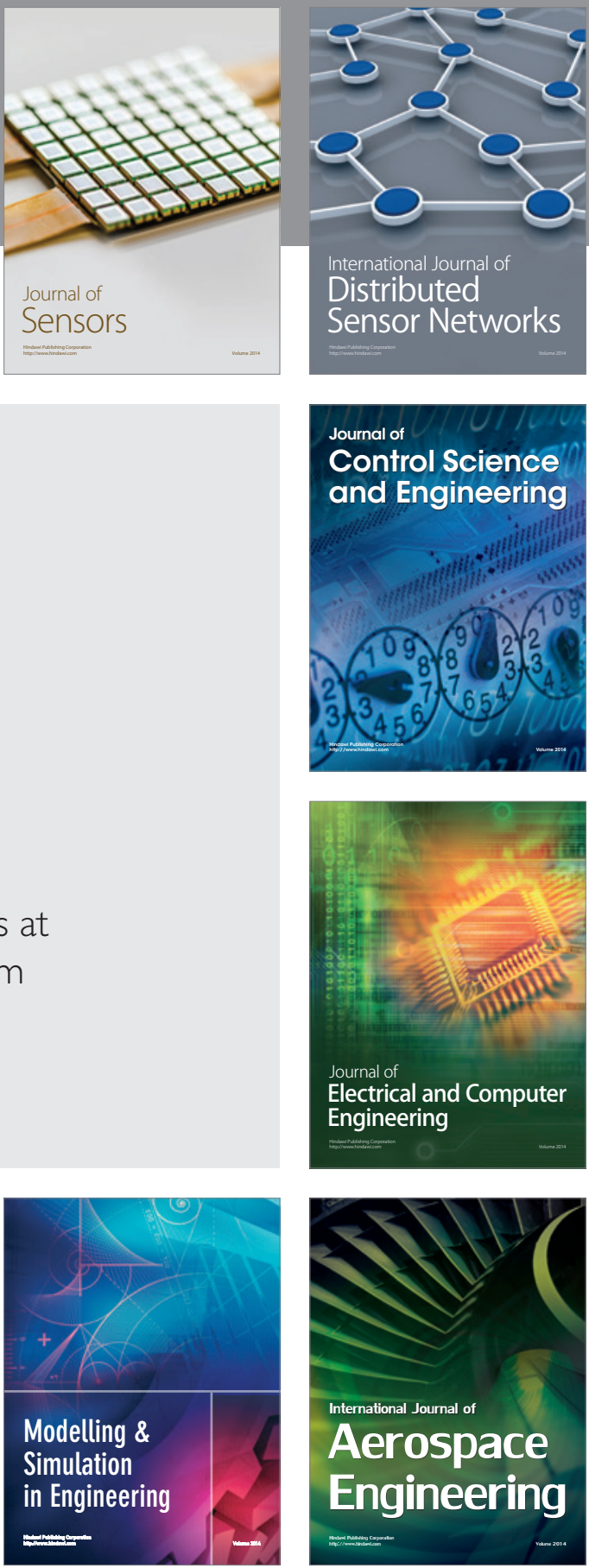

Journal of

Control Science

and Engineering
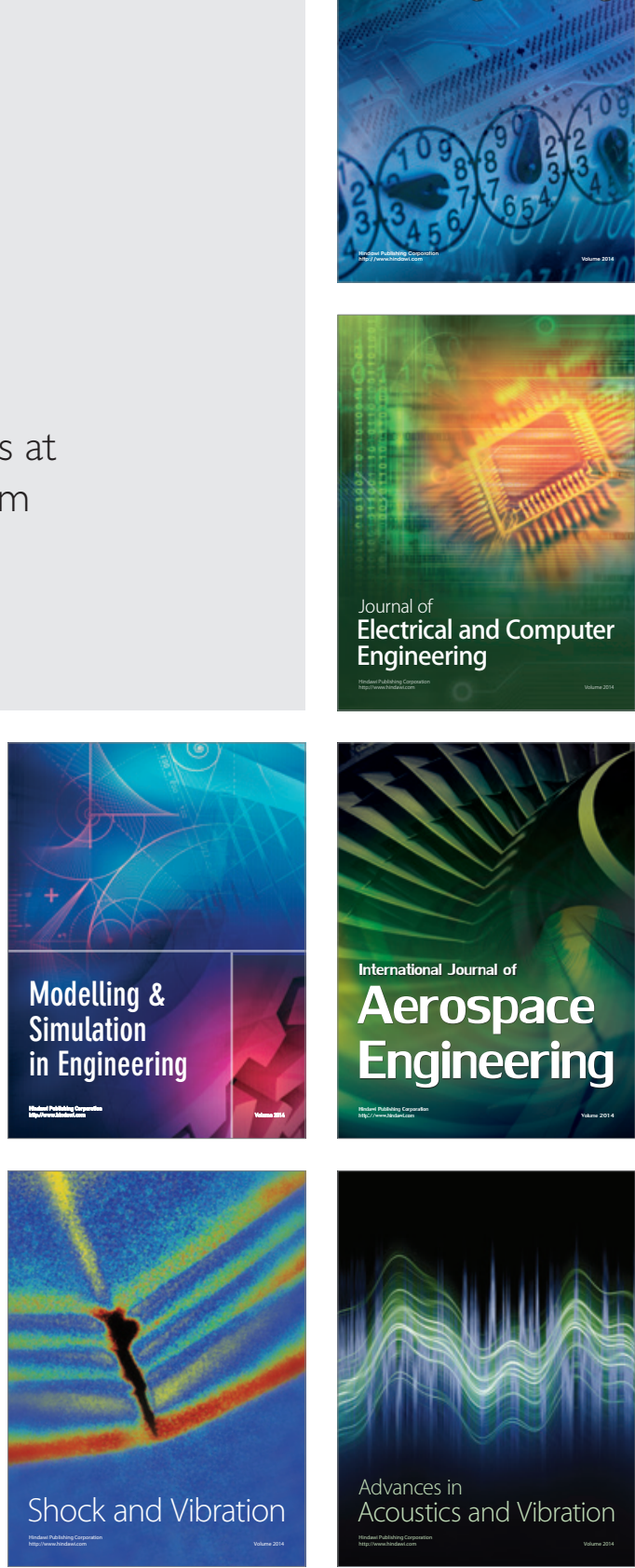